\title{
The Global Response to Tropical Heating in the Madden-Julian Oscillation during Northern Winter
}

\author{
By ADRIAN. J. MATTHEWS, ${ }^{1 *}$ BRIAN. J. HOSKINS ${ }^{2}$ and MICHIKO MASUTANI ${ }^{3}$ \\ ${ }^{1}$ Schools of Environmental Sciences and Mathematics, University of East Anglia, UK \\ ${ }^{2}$ Department of Meteorology, University of Reading, UK \\ ${ }^{3}$ National Centers for Environmental Prediction, Camp Springs, MD, USA
}

\begin{abstract}
Summary
A life cycle of the Madden-Julian oscillation (MJO) was constructed, based on 21 years of outgoing longwave radiation data. Regression maps of NCEP-NCAR reanalysis data for northern winter show statistically significant upper-tropospheric equatorial wave patterns linked to the tropical convection anomalies, and extratropical wave patterns over the North Pacific, North America, the Atlantic, the Southern Ocean and South America. To assess the cause of the circulation anomalies, a global primitive equation model was initialised with the observed three-dimensional winter climatological-mean flow and forced with a time-dependent heat source derived from the observed MJO anomalies. A model MJO cycle was constructed from the global response to the heating, and both the tropical and extratropical circulation anomalies generally matched the observations well. The equatorial wave patterns are established in a few days, while it takes approximately two weeks for the extratropical patterns to appear. The model response is robust and insensitive to realistic changes in damping and basic state. The model tropical anomalies are consistent with a forced equatorial Rossby-Kelvin wave response to the tropical MJO heating, although it is shifted westward by approximately $20^{\circ}$ longitude relative to observations. This may be due to a lack of damping processes (cumulus friction) in the regions of convective heating. Once this shift is accounted for, the extratropical response is consistent with theories of Rossby wave forcing and dispersion on the climatological flow, and the pattern correlation between the observed and modelled extratropical flow is up to 0.85 . The observed tropical and extratropical wave patterns accounts for a significant fraction of the intraseasonal circulation variance, and this reproducibility as a response to tropical MJO convection has implications for global medium-range weather prediction.
\end{abstract}

KEYwORDS: Madden-Julian oscillation Extratropical intraseasonal variability Rossby wave response Equatorial waves Tropical convection

\section{INTRODUCTION}

The Madden-Julian oscillation (MJO) is the dominant mode of intraseasonal variability in the tropical atmosphere and was first characterised by eastward-propagating deep tropical convection anomalies over the warm pool region and associated tropical circulation anomalies (Madden and Julian 1972). It was later shown that these circulation anomalies extended into the middle and high latitudes (e.g., Knutson and Weickmann 1987; Ferranti et al. 1990; Kiladis and Weickmann 1992; Hendon and Salby 1994; Higgins and Mo 1997). These extratropical circulation anomalies tend to take the form of wave trains over Asia, the North Pacific, North America, the Atlantic and the Southern Hemisphere. However, there are significant differences between the various studies, partly due to the different analysis methods used and partly due to the relatively short data sets that were available at the time.

As the extratropical circulation anomalies display energy dispersion away from the region of anomalous tropical convection, they have been interpreted as a Rossby wave response to the latent heat release associated with the tropical convection (Ferranti et al. 1990). In regions of anomalous tropical heating, there is a dynamical response with anomalous large-scale ascent and upper tropospheric divergence which acts as a Rossby wave source (Sardeshmukh and Hoskins 1988) for extratropical waves. Conversely, in regions of reduced convection and anomalous cooling, the tropical response is one of anomalous descent and upper-tropospheric convergent inflow. The direct global Rossby

* Corresponding author: School of Environmental Sciences, University of East Anglia, Norwich, NR4 7TJ, UK. E-mail: a.j.matthews@uea.ac.uk Internet: http://www.envam1.env.uea.ac.uk/ 
wave response to fixed tropical heating is established in about 15 days (Jin and Hoskins 1995). This can be compared to the average MJO period of approximately 45 days. Therefore, it might be expected that the extratropical anomalies at a given stage in the MJO cycle would be those effectively forced by the MJO heating from approximately 15 days previously, which would be very different from the current MJO heating anomalies. Hence, the time dependence of the heating is likely to be important.

However, there is more to the extratropical component of the MJO than a direct Rossby wave response to tropical heating on the climatological mean flow, at least in the Northern Hemisphere. Hsu (1996) showed that the MJO circulation anomalies over the North Pacific extracts energy from the mean flow by barotropic conversion. The observed anomalies have a similar pattern to the fastest-growing barotropic mode of the barotropically unstable Northern Hemisphere mean winter circulation (Simmons et al. 1983) which has a period of 45 days, close to the average period of the MJO. This mode is efficiently forced by the divergent flow associated with MJO heating in a barotropic model (Ferranti et al. 1990). However, Borges and Sardeshmukh (1995) found that all the barotropic modes on a realistic tropospheric flow are global and damped, and the least damped mode would take more than 20 days to emerge from arbitrary initial conditions, implying that the forcing of the extratropical flow is of primary importance compared to free normal mode growth. Therefore, the MJO extratropical circulation appears to be a mixture of a direct Rossby wave response to the tropical convection, which then triggers an extratropical structure that grows by extracting energy from the extratropical mean flow. Changes to the global circulation during the MJO cycle then affect the propagation characteristics of higher frequency waves, particularly over the North Pacific which could then feed back onto the MJO convection (Matthews and Kiladis 1999a). The momentum fluxes associated with these waves may then feed back onto the MJO circulation anomalies.

In the present study a long (21 year) data set of outgoing longwave radiation (OLR) and the recently available National Centers for Environmental Prediction-National Center for Atmospheric Research (NCEP-NCAR) reanalysis were used to identify the global circulation anomalies of the MJO. The reanalysis data set is free from the problems caused by changes to the operational analyses and incorporates extra observational data that was not available for the operational analyses (Kalnay et al. 1996). A series of numerical experiments using a primitive equation model is then described that shows the response of the global atmosphere to the MJO cycle of tropical heating anomalies. This response includes both the direct Rossby wave response to the heating anomalies and any subsequent anomaly growth that draws energy from the mean flow. It does not include any changes to the high-frequency waves and their feedback onto the MJO. The extratropical component of the MJO is then discussed in the light of these experiments.

\section{Data AND methodology}

The data sets and analysis techniques used in this study were described in detail in Matthews (2000). OLR was used as a proxy for deep tropical convection. The OLR data were obtained from National Oceanic and Atmospheric Administration (NOAA) polarorbiting satellites as a daily-mean, gridded, interpolated data set (Liebmann and Smith 1996). The data started on 1 June 1974 and ended on 16 September 1998, with missing data from 16 March to 31 December 1978, inclusive. The NCEP-NCAR reanalysis data were retrieved for the same period as the OLR data. Both data sets were on a $2.5^{\circ}$ longitude $\times 2.5^{\circ}$ latitude grid. After subtracting the time mean and first three annual harmonics, the data were passed through a 20-200-day band-pass Lanczos filter. 
Following Matthews (2000), the MJO life cycle was defined by an empirical orthogonal function (EOF) analysis of tropical 20-200-day filtered OLR. The leading two EOFs were used to define the MJO. Their principal component (PC) time series were then used as the basis for constructing linear regression maps of any other variable of interest. These regression maps were calculated using data from the 21 northern winters from December-February (DJF) 1974-75 to 1996-97, excluding 1977-78 and 1978-79. Progression through the MJO cycle was determined in terms of a phase angle that varied from $0^{\circ}$ to $360^{\circ}$. The $0^{\circ}$ phase corresponds to occasions when PC 1 is a maximum, and simultaneous regression maps for this phase were calculated using PC 1 as the dependent variable. The $90^{\circ}$ phase corresponds to occasions when $\mathrm{PC} 2$ is a maximum, and $180^{\circ}$ and $270^{\circ}$ to when PC 1 and PC 2 are at a minimum, respectively. Regression maps at intermediate phases were constructed by a linear combination of the regression maps based on PC 1 and PC 2. The MJO cycle has a nominal length of 48 days, hence the $0^{\circ}$ phase when $\mathrm{PC} 1$ is a maximum corresponds to $t=0$ days, the $90^{\circ}$ phase when $\mathrm{PC} 2$ is a maximum corresponds to $t=12$ days, and so on up to $t=48$ which, due to the periodicity of the analysis technique is equivalent to $t=0$ of the following MJO cycle. For full details, see Matthews (2000).

The statistical significance of these results was assessed using correlation maps between the PC time series and the gridded field of interest. The decorrelation time scale of the PC time series (or time between independent samples) is approximately 12 days (a quarter cycle). There are 21 winters of 90 days each, and therefore $n=(21 \times 90) / 12=157$ degrees of freedom. Applying a two-tailed test at the $95 \%$ level, under the null hypothesis that the fields are uncorrelated $(r=0)$, then the critical value of the Fisher transformed correlation coefficient is $B=1.96 / \sqrt{n-3}=0.158$ and the critical correlation coefficient is approximately $r=0.16$. In a further $a d$ hoc significance test, the data were split into two non-overlapping periods (DJF 1974/75-1986/87 and DJF 1987/88-1996/97). A set of regression maps was calculated for each of the two periods. The wind and streamfunction anomalies associated with all the observational features discussed in this paper are both formally significant at the $95 \%$ level and present in both sets of non-overlapping data.

\section{Observed MJO CyCle}

Regression maps of OLR and 200-hPa stream function anomalies are shown in Fig. 1 for every $1 / 8$ cycle or 6 days throughout the first half of the MJO life cycle. The OLR or convective anomalies show the familiar eastward propagation with a dipole structure over the warm pool, with negative OLR anomalies corresponding to regions of enhanced convection. Due to the linear nature of the analysis technique, the second half of the cycle is identical to the first half with a sign reversal (not shown). A detailed description was given in Matthews (2000).

Associated with the MJO tropical convective anomalies are global scale $200-\mathrm{hPa}$ circulation anomalies. In the tropics an anticyclonic couplet is collocated with or lies to the west of the enhanced convection and a cyclonic couplet is collocated with or lies to the west of the reduced convection. To the east of the enhanced (reduced) convection are equatorial westerly (easterly) anomalies. These tropical circulation features can be interpreted as an equatorial Rossby-Kelvin wave response to the tropical heating.

There are also coherent extratropical circulation anomalies. For example, at $t=0$ (Fig. 1a) there is an anticyclonic anomaly over the North Pacific centred at $45^{\circ} \mathrm{N}, 180^{\circ}$. The anomalous easterly flow along $30^{\circ} \mathrm{N}$ between it and the subtropical cyclonic anomaly to the south amounts to a weakening and westward retraction of the Asian-Pacific jet. 
(a) $t=0$

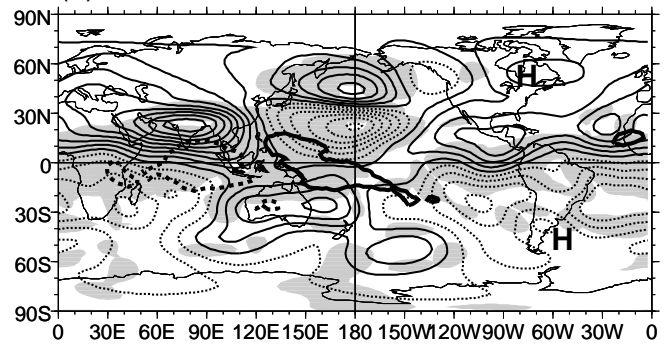

(b) $\mathrm{t}=6$

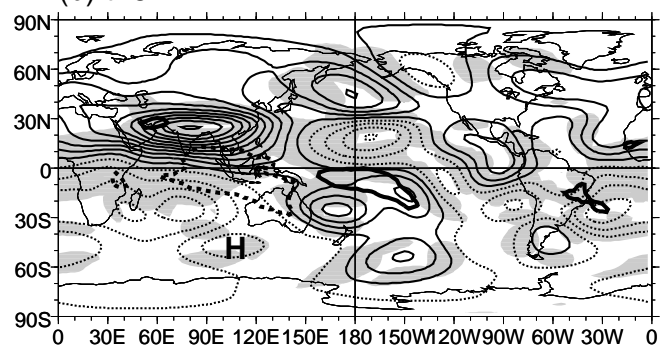

(c) $t=12$

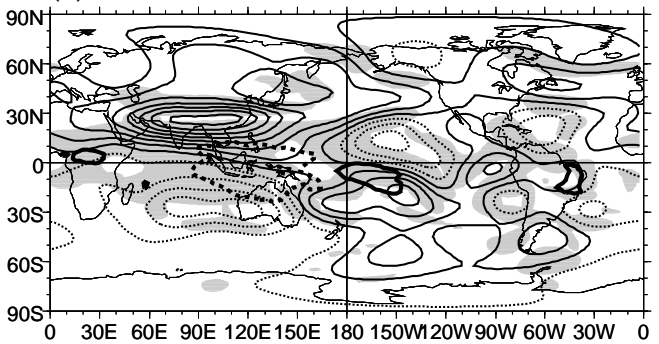

(d) $t=18$

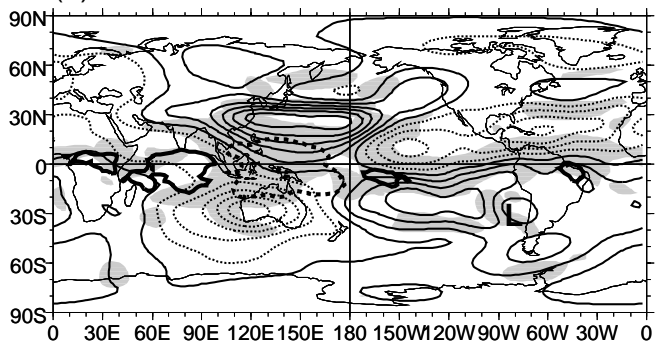

Figure 1. Regression maps of OLR and 200-hPa stream function for every 6 days of the first half of the MJO cycle, scaled to a deviation of PC1/2 $=2.0$. OLR is contoured heavily at $-10 \mathrm{~W} \mathrm{~m}^{-2}$ (dotted) and $10 \mathrm{~W} \mathrm{~m}^{-2}$ (solid). Stream function contour interval is $1.25 \times 10^{6} \mathrm{~m}^{2} \mathrm{~s}^{-2}$; negative contours are dotted. For clarity, the H and L symbols indicate selected local stream function maxima and minima, respectively. Regions where either the $u$ or $v$ component of the 200-hPa wind are locally significant at the $95 \%$ level are shaded.

Together with the cyclonic anomaly over western Canada and the anticyclonic anomaly over eastern Canada, these circulation anomalies form a wave train over the Pacific-North American region that is reminiscent of the Pacific-North American (PNA) pattern but is shifted westward.

By $t=6$ (Fig. 1b) this wave pattern exhibits downstream dispersion, with a weakening of the upstream centres over the North Pacific and western Canada and a strengthening of the downstream anticyclone over eastern Canada, together with the establishment of anomalous westerly flow extending across northern Europe and a short-wavelength wave train that propagates southeastward across the Atlantic, with cyclonic curvature over the subtropical Atlantic and reinforcement of an existing anticyclonic anomaly over the eastern tropical Atlantic.

At $t=0$ in the MJO cycle there is also an anticyclone couplet about the equator over the eastern Pacific. The equatorial easterly anomalies between the two anticyclones can be interpreted as the equatorial Kelvin wave response to the reduced heating over the western Pacific, but the westerly anomalies on the poleward flanks of the anticyclones can not. The OLR anomalies over South America are very weak and this does not appear to be an equatorial Rossby wave response to anomalous tropical convection there. Instead, it seems to be part of a larger scale northwest-southeast oriented wave train with a further cyclonic anomaly over southern South America, indicated by an "H" in Fig. 1a. This wave train shows southeastward energy dispersion and phase propagation through the equatorial eastern Pacific westerly duct consistent with barotropic Rossby wave propagation (Hoskins and Ambrizzi 1993; Matthews and Kiladis 1999b), as by $t=6$ and $t=12$ (Fig. 1b,c) the anticyclonic anomaly that was just north of the equator over the eastern Pacific has weakened and moved to the equator at $90^{\circ} \mathrm{W}$, while the cyclonic anomaly over southern South America has strengthened. 
There are other coherent extratropical circulation anomalies in the Southern Hemisphere. A weak wave train disperses from the subtropical anticyclonic anomaly over the southern Indian Ocean at $t=0$ (Fig. 1a). This takes the form of a cyclonic curvature to the flow near $50^{\circ} \mathrm{S}, 110^{\circ} \mathrm{E}$ at $t=0$ and then strengthens to include a closed contour at $t=6$, indicated by an " $\mathrm{H}$ " in Fig. 1b. Downstream there is an anticyclonic curvature to the flow at $60^{\circ} \mathrm{S}, 150^{\circ} \mathrm{E}$.

The fraction of variance of the $200-\mathrm{hPa}$ circulation that can be accounted for by the MJO is given by the square of the correlation coefficient between the $\mathrm{PC} 1 / 2$ time series and the time series of $200-\mathrm{hPa}$ zonal or meridional wind at a particular grid point. Locally, the MJO accounts for up to $54 \%$ of the 20-200-day filtered 200-hPa wind field in the tropics and up to $27 \%(10 \%)$ in the Northern (Southern) Hemisphere extratropics. The very broad 20-200-day band-pass filter was used to prevent the signal from one MJO event being smeared into the next event (Matthews 2000). However, most of the MJO signal lies in a much narrower frequency band. When the analysis was repeated using 30-70-day filtered data, the fraction of variance accounted for by the MJO rises to $70 \%$ in the tropics, and 36\% (18\%) in the Northern (Southern) Hemisphere extratropics. This is a substantial portion of the variance and emphasises the importance of the MJO for medium-range weather prediction, even for the extratropics.

To give an indication of the sensitivity of this analysis to the choice of OLR as the key variable and to the specific filtering, level and data set used, results are now given for an earlier independent analysis performed on 150 and 850-hPa stream function from European Centre for Medium Range Weather Forecasting (ECMWF) initialised analyses for the ten DJF seasons from 1982/83 to 1991/92. The data was first passed through a 30-day low-pass Butterworth filter, then a best-fit quadratic curve was subtracted from each individual season to remove the annual cycle and any interannual variability. The leading modes of an EOF analysis of this joint 150 and $850-\mathrm{hPa}$ stream function are shown in Fig. 2 (150-hPa fields only). EOF 1 (Fig. 2a) corresponds very closely to the regressed $200-\mathrm{hPa}$ stream function anomalies at $t=0$ in the MJO cycle (Fig. 1a), and EOF 2 (Fig. 2b) corresponds very closely to the 200-hPa stream function anomalies a quarter of a cycle later, at $t=12$ (Fig. 1c). Hence, the global MJO circulation anomalies presented are were both strongly linked to tropical convection and represent the dominant intraseasonal mode of global atmospheric variability in their own right.

Figure 2. EOF analysis of joint $150 / 850-\mathrm{hPa}$ intraseaonally filtered streamfunction from ECMWF analyses. The $150-\mathrm{hPa}$ fields of (a) EOF 1 (contour interval is $1 \times 10^{6} \mathrm{~m}^{2} \mathrm{~s}^{-2}$ ) (b) EOF 2 (contour interval is $\left.5 \times 10^{5} \mathrm{~m}^{2} \mathrm{~s}^{-2}\right)$. Negative values are stippled.

The observed global circulation anomalies associated with tropical MJO convection are consistent with many previous studies that based their analysis on tropical convective anomalies (e.g., Knutson and Weickmann 1987; Ferranti et al. 1990; Kiladis and Weickmann 1992; Hsu 1996). In particular, the extratropical circulation anomalies in the 
North Pacific near the date line and over the northeastern Pacific are robust features of all these studies. In these studies, the position of the downstream anomaly over eastern North America is centred over eastern Canada consistent with results shown here. In other analyses that were based on an extratropical index (e.g. Higgins and Mo 1997), this downstream anomaly is located over the southeastern United States, consistent with the classical PNA pattern.

\section{Fixed heAting EXPeriments}

The observed circulation anomalies associated with tropical MJO convection are global in scale. In this section a series of numerical model experiments are described that were designed to assess the hypothesis that the global circulation anomalies arise as a direct response to the MJO convective heating. Following Jin and Hoskins (1995), a primitive equation spectral transform model was used. For full details of the setup used here, see Matthews and Kiladis (1999b). In summary, the model was run at T42 horizontal resolution with 12 vertical sigma levels. It was initialised about a three-dimensional DJF climatological-mean basic state. A constant forcing term was applied throughout the model integration to maintain the basic state.

First, a set of integrations was performed where a fixed heating term was applied to represent the effects of latent heat release from deep convection at a fixed phase of the MJO. Such latent heating was a maximum in the mid-troposphere, hence the heating rate $H$ at $400 \mathrm{hPa}$ was estimated directly from the NCEP-NCAR reanalysis data, as the residual in the thermodynamic equation. Daily maps of 400-hPa $H$ were calculated which were then filtered and regressed against the PC time series of OLR. A staggered set of 48 such integrations was performed; the first integration with the heating from $t=0$, the second with the heating from $t=1$, and so on, up to the 48th integration with the heating from $t=47$. Only the heating anomalies over the warm pool region $\left(40^{\circ} \mathrm{E}\right.$ to $140^{\circ} \mathrm{W}$ and $20^{\circ} \mathrm{S}$ to $15^{\circ} \mathrm{N}$ ) were used. The horizontal structure of the $400-\mathrm{hPa} H$ anomalies at $t=0$ and $t=12$ closely matched the corresponding MJO OLR anomalies (Fig. 3). The idealised vertical profile of the heating followed that of Matthews and Kiladis (1999b) and Jin and Hoskins (1995) with a mid-tropospheric peak at $400 \mathrm{hPa}$, consistent with that generally found to be implied by the analysed observational data.

After approximately 25 days of integration, baroclinic waves begin to dominate (Jin and Hoskins 1995), but during the first 25 days the direct response to the imposed fixed MJO heating anomalies can be diagnosed. One aspect of the results of these 48 integrations is summarised in Fig. 4. For a given phase of the MJO, here $t=0$ (which is equivalent to $t=48$ ), the pattern correlation coefficient between the observed $200-\mathrm{hPa}$ zonal wind anomaly field and the 200-hPa zonal wind field for each day of each integration was calculated (Fig. 4a) Here, the pattern correlation was only calculated between $25^{\circ} \mathrm{S}$ and $25^{\circ} \mathrm{N}$ to assess the modelled equatorial wave response.

Given that the observed $t=0$ ( or $t=48$ ) phase of the MJO will be comprised of the response to the observed time-dependent heating over the previous few days, and that it takes approximately 10 days for the full equatorial wave response to be established, we might expect the best match with the observed MJO at $t=0(t=48)$ to be from about day 10 in the integration with the heating at a slightly earlier phase, say $t=43$, which would correspond qualitatively to an average of the heating anomalies for the previous 10 days. However, the highest pattern correlations (Fig. 4a) are clearly from the integration with the heating from $t=2$, i.e., at a later phase than the target $t=0$. The highest correlation coefficient is 0.83 at day 16 of this integration. 
(a) $t=0$

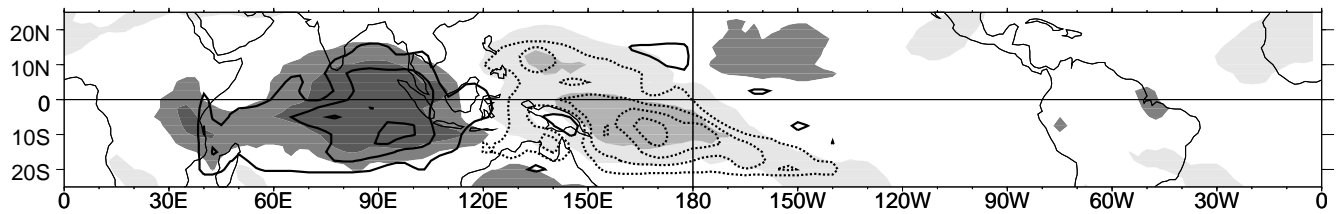

(b) $t=12$

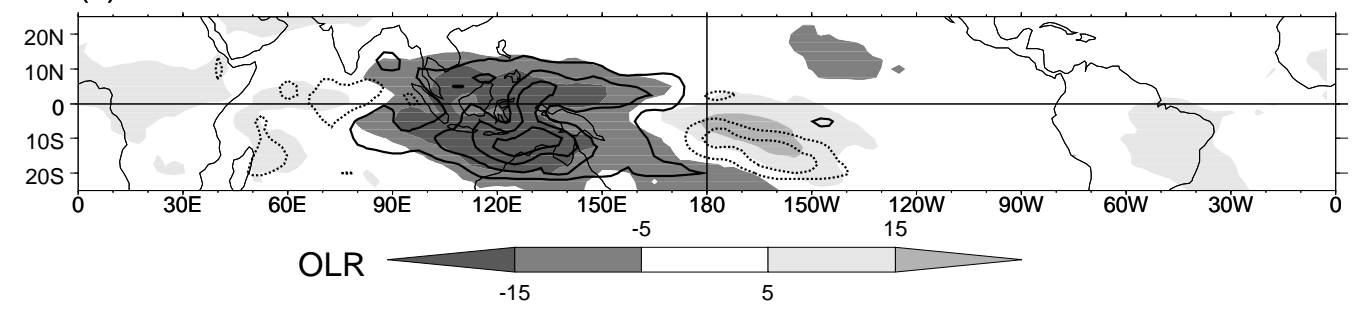

Figure 3. As in Fig. 1 but for regression maps of OLR and 400-hPa $H$ at (a) $t=0$, (b) $t=12$. The 400 -hPa $H$ contour interval is $0.5 \mathrm{~K} \mathrm{day}^{-1}$; negative contours are dotted, and the first positive contour is at $0.25 \mathrm{~K} \mathrm{day}^{-1}$. OLR is shaded darkly below $-5 \mathrm{~W} \mathrm{~m}^{-2}$ and lightly above $5 \mathrm{~W} \mathrm{~m}^{-2}$ (see legend).

(a)

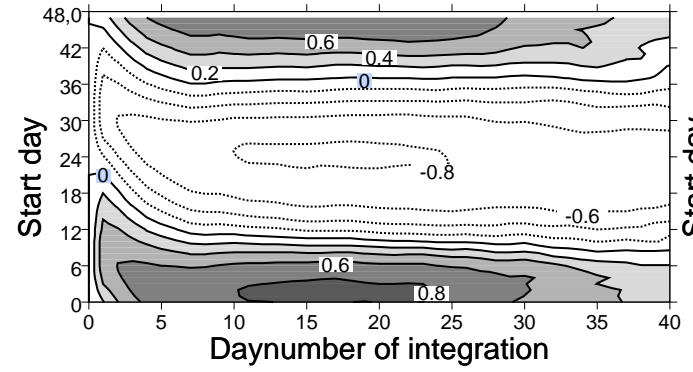

(b)

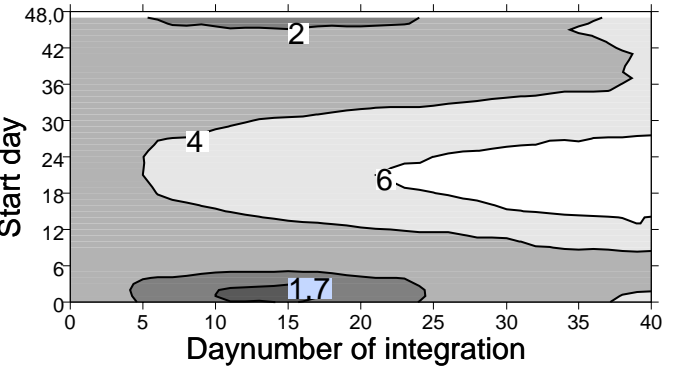

Figure 4. Fixed heating integrations. (a) The 200-hPa anomalous zonal wind pattern correlation coefficient between each day ( $x$ axis) of each integration (the day in the MJO cycle from which the heating is taken from is shown on the $y$ axis) and the observed MJO at $t=0$, calculated over the tropical domain from $25^{\circ} \mathrm{S}$ to $25^{\circ} \mathrm{N}$. (b) As in (a) except for the root mean square error. Units are $\mathrm{m} \mathrm{s}^{-1}$.

This apparent paradox can be traced to a systematic error in the model response. The modelled equatorial Rossby wave quadrupole response to the heating dipole lies too far to the west of the heating anomalies, compared to observations. This westward shift can be "corrected" by unrealistically increasing everywhere the strength of the damping applied to the model dynamical fields. The $200-\mathrm{hPa}$ stream function response at day 15 to fixed heating from $t=0$ in the MJO cycle is shown in Fig. 5a. The tropical quadrupole response lies too far to the west of the heating. For example, the centre of the anomalous anticyclone in the Northern Hemisphere is at $60^{\circ} \mathrm{E}$. When the experiment was repeated but with an unrealistically strong damping with a time scale of 1 day applied at all model levels, the net effect is to locate the tropical quadrupole response above the heating (Fig. 5b); the centre of the anomalous anticyclone is now at $80^{\circ} \mathrm{E}$. The overall response is much weaker and is confined to the heating region. A physical interpretation is that the divergence above the anomalous heating leads to an anticyclonic vorticity anomaly there. In the standard integration (Fig. 5a) this then moves westward via the Rossby wave propagation mechanism. However, if the drag or damping is very large (Fig. 5b), the vorticity anomaly is strongly damped as it moves westward away from the forcing 
region, with the result that the response is weaker and located above the heating. Such a large damping could possibly be justified locally in the region of heating as cumulus friction (e.g., Mapes and Wu 2001), but this is beyond the scope of this study. Whether the cause of the westward shift of the model response is a lack of cumulus friction or not, the best match with the $t=0$ observed tropical response is from a model integration whose imposed heating is shifted eastward, or later in the MJO cycle, at $t=2$.

(a)

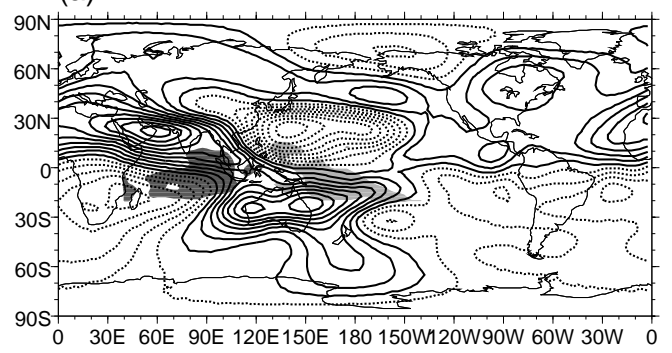

(b)

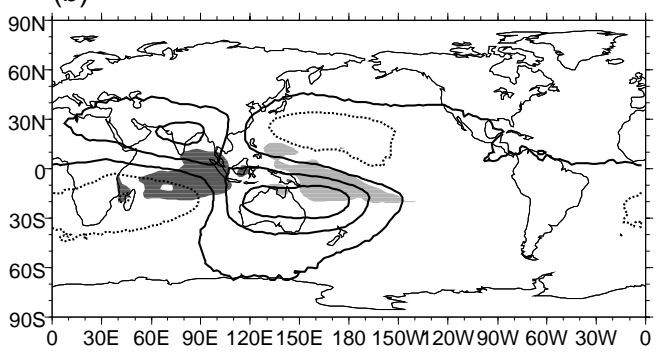

Figure 5. Day 15 anomalous 200-hPa stream function in the model forced with fixed heating at $t=0$ of the MJO cycle. (a) Standard integration. (b) 1-day damping at all levels. Contour interval is $1.25 \times 10^{6}$ $\mathrm{m}^{2} \mathrm{~s}^{-1}$; negative contours are dotted. The 400-hPa heating anomaly is shaded darkly below $0.5 \mathrm{~K}_{\text {day }}{ }^{-1}$ and lightly above $0.5 \mathrm{~K} \mathrm{day}^{-1}$.

An alternative measure of the agreement between the modelled and observed fields is the root mean square error (Fig. 4b). The minimum error is for day 16 of the integration with the heating from $t=1$ of the MJO cycle, in very good agreement with the correlation calculations. The error increases rapidly with time in each integration from around day 25 , as baroclinic waves begin to dominate the model solution.

Similar results were obtained for other phases of the MJO. At each phase of the MJO, the best match was obtained from an integration with the fixed heating field taken from 1-2 days after the target date. Hence, the systematic westward erroneous shift of the response relative to the heating is present throughout the cycle. The maximum pattern correlation ranges from 0.83 at $t=0$ to 0.64 at $t=39$. Hence, an excellent to reasonable simulation of the tropical MJO circulation was modelled as a response to fixed MJO heating anomalies, provided this westward shift of the model response is taken into account.

\section{Time-VARYing HeATING EXPERIMENTS}

\section{(a) Tropical divergent response to heating}

A second set of 48 staggered integrations was then carried out to assess the response to the time-varying MJO heating. Tropical heating anomalies over the warm pool were calculated every day from the observed MJO and linearly interpolated for intermediate times. The first integration started at $t=0$ of the MJO cycle; the second started at $t=1$, and so on, up to the 48 th integration, which started at $t=47$ of the MJO cycle. The imposed MJO heating was cyclical with a period of 48 days. Hence, the later integrations carried on into a second cycle.

The observed MJO tropical diabatic heating anomalies are mainly balanced by adiabatic cooling from large-scale anomalous ascent. For example, the negative vertical pressure velocity $(\omega)$ anomalies (corresponding to anomalous ascent) over the tropical Indian Ocean at $t=0$ (Fig. 6a) are coincident with the anomalous heating there (Fig. 3a). 
There is also anomalous descent (positive $\omega$ anomalies) over the western Pacific at this time, coincident with anomalous diabatic cooling there.

(a) $\mathrm{t}=0$ Observations

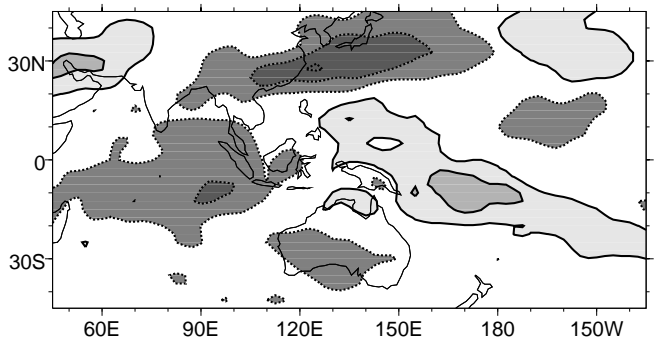

(b) $t=0$ Model

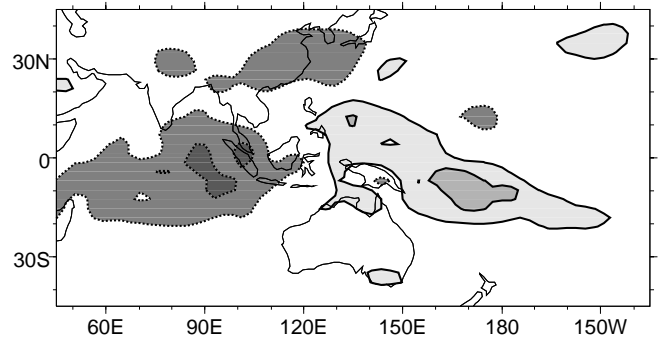

Figure 6. (a) The 400-hPa $\omega$ anomalies from the observed MJO cycle at $t=0$. (b) The corresponding field from day 9 of the model integration started at $t=39$. Contour interval is $0.16 \mathrm{~Pa} \mathrm{~s}^{-1}$; first positive contour is at $0.08 \mathrm{~Pa} \mathrm{~s}^{-1}$. Negative contours are dotted, and negative (positive) values are shaded darkly (lightly).

In the model experiments, an anomalous vertical circulation arose as a response to the imposed time-varying heating anomaly. For example, at day 9 in the integration starting at $t=39$, the anomalous ascent in Fig. $6 \mathrm{~b}$ represents the model response to the previous 9 days of MJO tropical heating. This day corresponds to $t=0$ in the MJO cycle and the regions of ascent and descent closely matched the observed field in Fig. 6a. Note there is no spatial or time lag in this response of the vertical velocity (and hence the upper tropospheric divergence) to the heating. The erroneous westward shift in the model arises when the rotational flow (the equatorial Rossby wave response) is forced by the divergence anomalies.

\section{(b) Construction of a model MJO cycle}

The results of the 48 staggered integrations with time-dependent heating, when compared with the observed MJO at $t=0$, are summarised in Fig. 7. If the modelled and observed response developed at the same rate, the maximum correlations would be expected to lie along the thick diagonal line extending from the top left corner, which has a gradient of -1 . For any given integration that starts $\tau$ days before the target time (of $t=48$ in Fig. 7a), this line passes through day $\tau$ of that integration, which would be expected to match the observations best.

However, the band of maximum correlation lies above this line. The maximum correlation coefficient $(r=0.82)$ is found at day 11 of the integration that started at $t=42$ in the MJO cycle. This is consistent with a time scale of approximately 10-12 days for the equatorial wave response to be set up, but it might have been expected that day 11 of the integration starting at $t=37$, i.e., 11 days before the target time of $t=48$, would exhibit the highest correlation. This shift from the $t=37$ start time to that at $t=42$ is consistent with the erroneous westward shift of the tropical response found in the integrations with fixed heating, and this error can now be quantified. The difference between the integration that gave the best fit and the integration that would be expected to give the best fit is 5 days, which corresponds to a westward shift of approximately $20^{\circ}$ longitude, given the eastward propagation speed of approximately $5 \mathrm{~m} \mathrm{~s}^{-1}$ for the convection anomalies. The pattern correlations for day 11 of the integrations have been replotted in Fig. 7b to show this lag throughout the MJO cycle. At $t=0$ in the cycle the maximum correlation at day 11 of an integration is found with a lag of 5 days, consistent with Fig. 7a. Throughout the MJO cycle, this lag is fairly consistent, varying from 5 
(a)

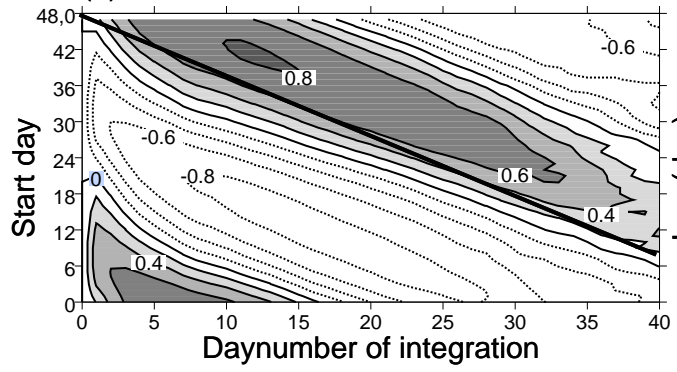

(b)

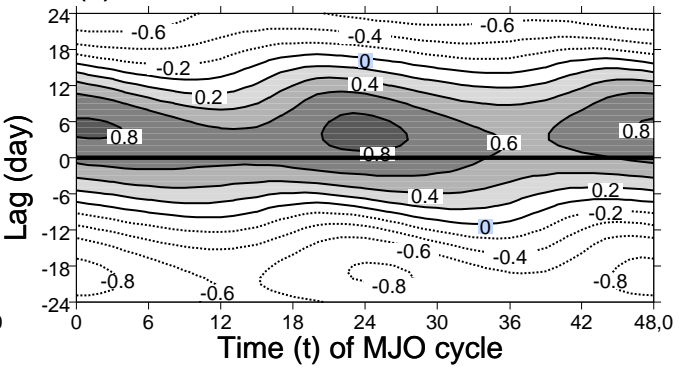

Figure 7. Time-dependent heating integrations. (a) The 200-hPa anomalous zonal wind pattern correlation coefficient between each day (on $x$ axis) of each integration (start day is shown on $y$ axis) and the observed $\mathrm{MJO}$ at $t=0$, calculated over the tropical domain from $25^{\circ} \mathrm{S}$ to $25^{\circ} \mathrm{N}$. The thick diagonal line indicates where the band of maximum correlation would be expected to lie if the model anomalies developed at the same rate as the observations. Contour interval is 0.2 , and negative contours are dotted. (b) As in (a) but for the correlation between each day of the MJO cycle (on the $x$ axis) and day 11 of the model integrations. The $y$ axis shows the lag between day 11 (the end day) of the relevant model integration and the time of the MJO cycle.

days at $t=0$ to 2 days at $t=12$ then back up to 5 days at $t=24$, with the second half of the cycle following a similar pattern. The root mean square error calculations give very similar results to those based on correlation patterns.

Given that the maximum pattern correlation between the observed $(t=0)$ and modelled anomalies does not increase from the fixed heating experiments to the time-varying heating experiments (in fact at $t=0$ it decreases slightly from 0.83 to 0.82 ) the value of including the time-varying heating can be questioned. However, the best match from the fixed heating experiments requires the heating field from 1-2 days after the target MJO phase, while the best match from the time-varying heating experiments requires the heating field from approximately 6 days before the target phase, onwards. In a predictive sense, it is preferential to use the time-varying heating.

The anomalous tropical $200-\mathrm{hPa}$ vector wind field from day 11 of the integration starting at $t=42$ of the MJO cycle is shown in Fig. 8 by the black arrows, together with the observed anomalous wind vectors (grey arrows) at $t=0$ of the MJO cycle (the target time). In general, there is excellent agreement between the modelled and observed wind fields, especially where the observations are statistically significant (shaded areas). The tropical response to MJO heating on a realistic three-dimensional basic state modelled here can be compared to the response on a zonally symmetric basic state (Hendon and Salby 1996). The three-dimensional basic state used here enables more of the details of the observed flow to be simulated, especially in the Western Hemisphere.

\section{(c) The model MJO cycle in the extratropics}

In this section, a composite life cycle of the MJO is constructed. We are primarily concerned with the extratropical response to the MJO, which is much stronger in the Northern Hemisphere than the Southern Hemisphere. First, we show the correlation patterns calculated over $30^{\circ} \mathrm{N}$ to $90^{\circ} \mathrm{N}$ (Fig. 9) at day 19 of each integration and the time of the MJO cycle, as in Fig. 7b. Note that a longer time is needed (19 days) for the best extratropical response, compared to only 11 days for the best tropical response. Again, this is consistent with the response to fixed tropical heating described in Jin and Hoskins (1995). In general, there is a fairly broad band of high correlations with an average lag of 6 days. By varying the length of the integration, and the lag, we can slightly improve the correlations or reduce the root mean square error. 


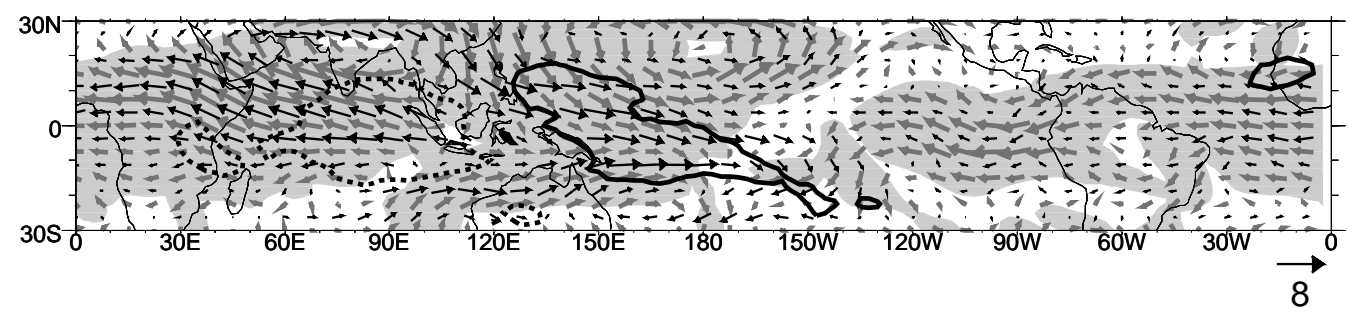

Figure 8. Regression map of observed 200-hPa anomalous wind vectors (grey arrows) and anomalous OLR (heavy contours) at $t=0$ of the MJO cycle. Regions where either the $u$ or $v$ component is locally significant at the $95 \%$ level are shaded. The OLR anomaly contours are at $-10 \mathrm{~W} \mathrm{~m}^{-2}$ (dashed) and $10 \mathrm{~W} \mathrm{~m}^{-2}$ (solid). Anomalous modelled 200 -hPa wind vectors from day 11 of the integration starting at $t=42$ are shown by the black arrows. The reference vector has magnitude $8 \mathrm{~m} \mathrm{~s}^{-1}$.

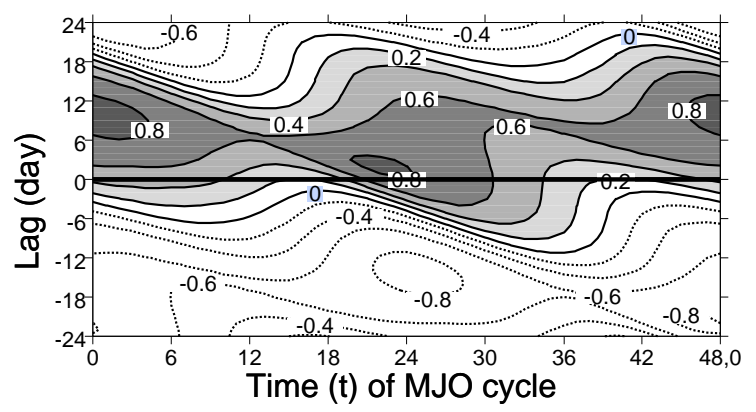

Figure 9. As in Fig. 7b, but with correlations calculated from $30^{\circ} \mathrm{N}$ to $90^{\circ} \mathrm{N}$.

Hence, the composite MJO life cycle was constructed for each phase of the cycle by selecting the day from all 48 integrations for which the model 200-hPa $u$ wind field had the lowest root mean square error with the observed field for that phase. For the $t=0$ phase, the day 19 response in the integration starting at $t=39$ (a lag of 10 days) had the lowest error (Fig. 10a), and also the highest pattern correlation coefficient of $r=0.86$; this increased to $r=0.93$ in the North Pacific region only $\left(30^{\circ} \mathrm{N}-90^{\circ} \mathrm{N}, 120^{\circ} \mathrm{E}-\right.$ $\left.120^{\circ} \mathrm{W}\right)$. There is excellent agreement between this model field and the observed field in the Northern Hemisphere. In particular, the wave train over the Pacific-North American region has been well reproduced, with an anticylonic anomaly over the central North Pacific. Downstream of this is an anomalous cyclone near Alaska, although the exact position of this differs between the model and observations. However, this may be due to sampling error in the observations as the southerly flow on the eastern flank of the cyclone is the only part of this feature that is significant in the observations, and the model agrees well here. The model response also agrees well with the observed anticyclone over eastern Canada and the cyclone over the North Atlantic.

In the Southern Hemisphere, the agreement between the modelled and observed fields is poor. This is partly due to the model field in Fig. 10a having been selected based on its agreement with the observations in the northern extratropics $\left(30^{\circ} \mathrm{N}-90^{\circ} \mathrm{N}\right)$, but even if it is selected based on agreement in the southern extratropics $\left(90^{\circ} \mathrm{S}-30^{\circ} \mathrm{S}\right)$ the maximum pattern correlation is only $r=0.61$. The most prominent observed feature in the Southern Hemisphere is a cyclonic anomaly centred at $50^{\circ} \mathrm{S}, 150^{\circ} \mathrm{W}$. This does have a counterpart in the model field, but this is shifted to the southwest, centred at $60^{\circ} \mathrm{S}$, $180^{\circ} \mathrm{W}$. This mismatch can be traced back to the tropics; the model subtropical cyclonic response to the reduced heating over the western Pacific is too far west, centred at $30^{\circ} \mathrm{S}$, 

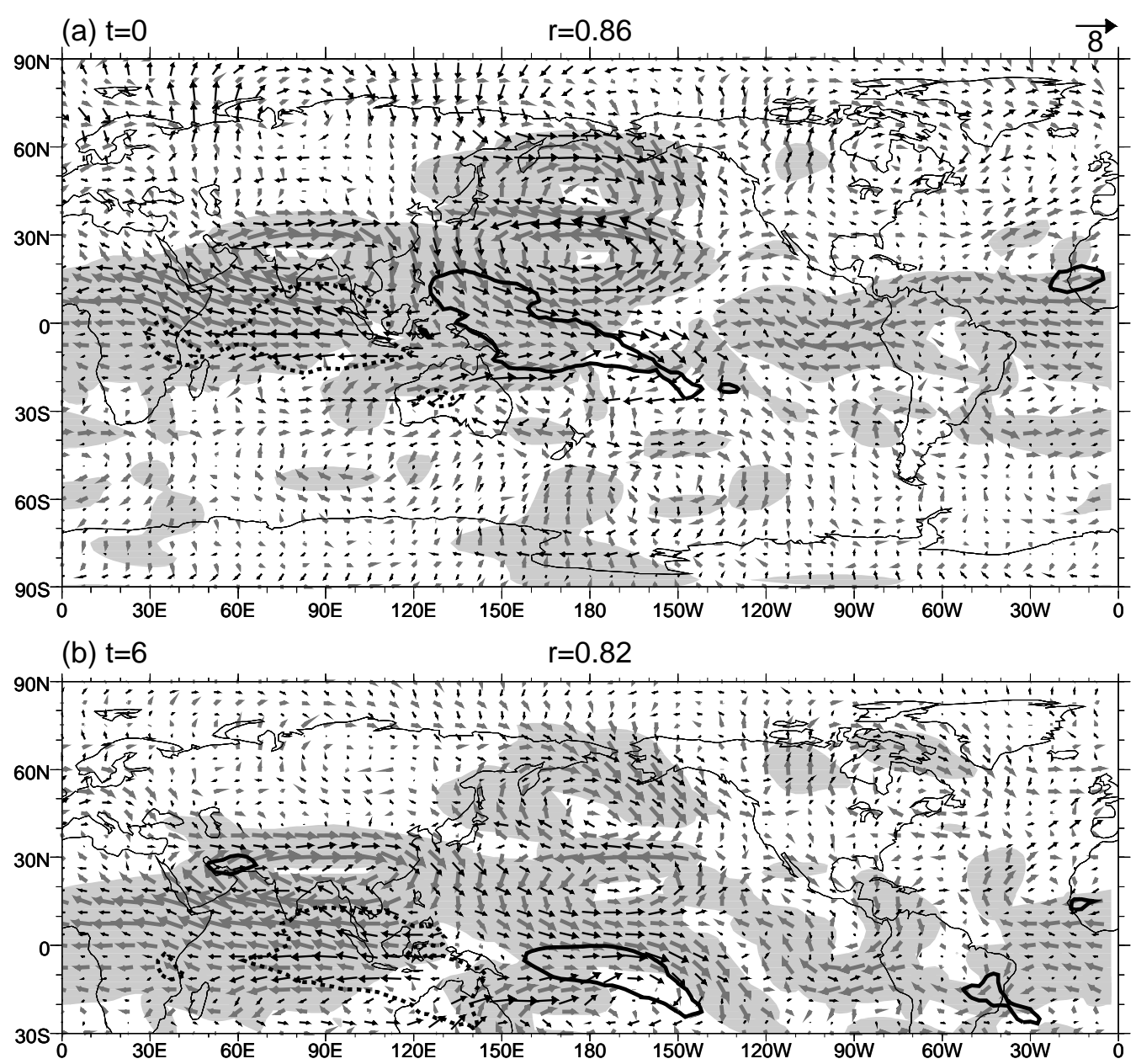

Figure 10. Regression maps of observed 200-hPa anomalous wind vectors (grey arrows) and anomalous OLR (heavy contours). Regions where either the $u$ or $v$ component is locally significant at the $95 \%$ level are shaded. The OLR anomaly contours are at $-10 \mathrm{~W} \mathrm{~m}^{-2}$ (dashed) and $10 \mathrm{~W} \mathrm{~m}^{-2}$ (solid). Anomalous modelled $200-\mathrm{hPa}$ wind vectors from the selected integrations are shown by the black arrows. The reference vector has magnitude $8 \mathrm{~m} \mathrm{~s}^{-1}$. (a) Observed field at $t=0$, day 19 model field from integration starting at $t=39$. (b) $t=6$, day 14 from integration starting at $t=46$. (c) $t=12$, day 15 from integration starting at $t=1$. (d) $t=18$, day 20 from integration starting at $t=2$. The pattern correlation coefficient $r$ between the observed and modelled fields is shown above each panel.

$150^{\circ} \mathrm{E}$, compared to $30^{\circ} \mathrm{S}, 170^{\circ} \mathrm{E}$ in the observations.

The poor performance of the model in the Southern Hemisphere extratropics could be related to the differences in basic state. In the Northern Hemisphere, the time mean flow has strong zonal asymmetries and the extratropical response will tend to develop in preferred locations, as described above. However, the time mean flow in the Southern Hemisphere is more zonally symmetric and there will not be such a tendency for development in preferred regions. Hence the extratropical response will be more sensitive to the exact pattern of tropical forcing and errors in the model tropics would carry through to the extratropics.

The model field that best agrees with the observed MJO at $t=6$ in the Northern Hemisphere $\left(30^{\circ} \mathrm{N}-90^{\circ} \mathrm{N}\right)$ is the day 14 field from the integration starting at day 46 of 
the cycle (a lag of 6 days; Fig. 10b); the pattern correlation is 0.82. Again, individual modelled features correspond well with the observations, especially where the latter are significant. However, at $t=12$, the agreement is significantly worse. The best match only has a pattern correlation of 0.64 and occurs at day 15 in the integration starting at $t=1$ of the MJO cycle a lag of 4 days; (Fig. 10c). The observed significant features over the North Pacific are reproduced well, but the model does not capture the observed North Atlantic features at all, even though they are significant over a large area. By $t=18$, the model simulation has improved. The best match is on day 20 of the integration starting at $t=2$ of the cycle, and the pattern correlation is 0.75 (a lag of 4 days; Fig. 10d). Again, the significant observed features over the North Pacific region are well reproduced, and there is an anticyclonic anomaly over the North Atlantic comparable with the observed features there, although it is not as zonally elongated and is centred further north. Overall, there is a good to excellent agreement between the modelled response in the tropics and Northern Hemisphere extratropics to MJO heating anomalies during the first half of the MJO cycle and the observations.
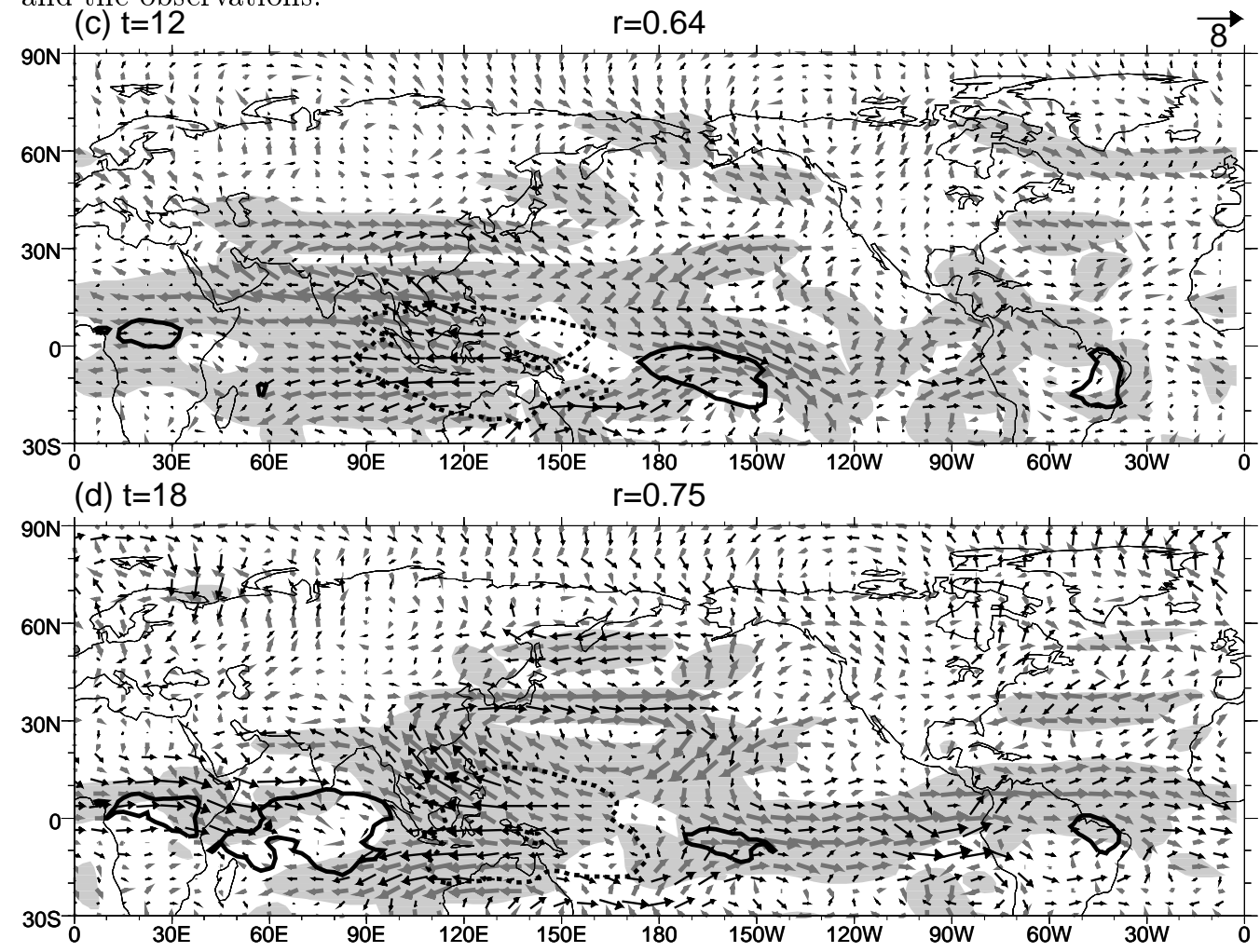

Fig. 10 (cont).

To a first approximation, the model response is linear, as the model anomalies during the second half of the cycle are similar to those in the first half, but with a sign change. However, there are differences due to nonlinear terms. For example, at $t=30$ in the MJO cycle, the model field that best agrees with the observations in the Northern Hemisphere extratropics is the day 14 field from the integration starting at $t=21$ of the cycle. This is almost exactly half a cycle after the best model fit for $t=6$ (Fig. 10b), which is an indication of the underlying linearity, although the pattern correlation is only 0.72 at $t=30$ compared to 0.82 at $t=6$. The model anomaly pattern for $t=30$ (not shown) is 
qualitatively similar to that for $t=6$ (Fig. 10b) with a sign change. The sum of the best fit model fields for $t=6$ and $t=30$ is shown in Fig. 11. The difference of this from zero is a measure of the nonlinearity of the response. Note the different scaling of the vectors between Fig. 10 and Fig. 11.

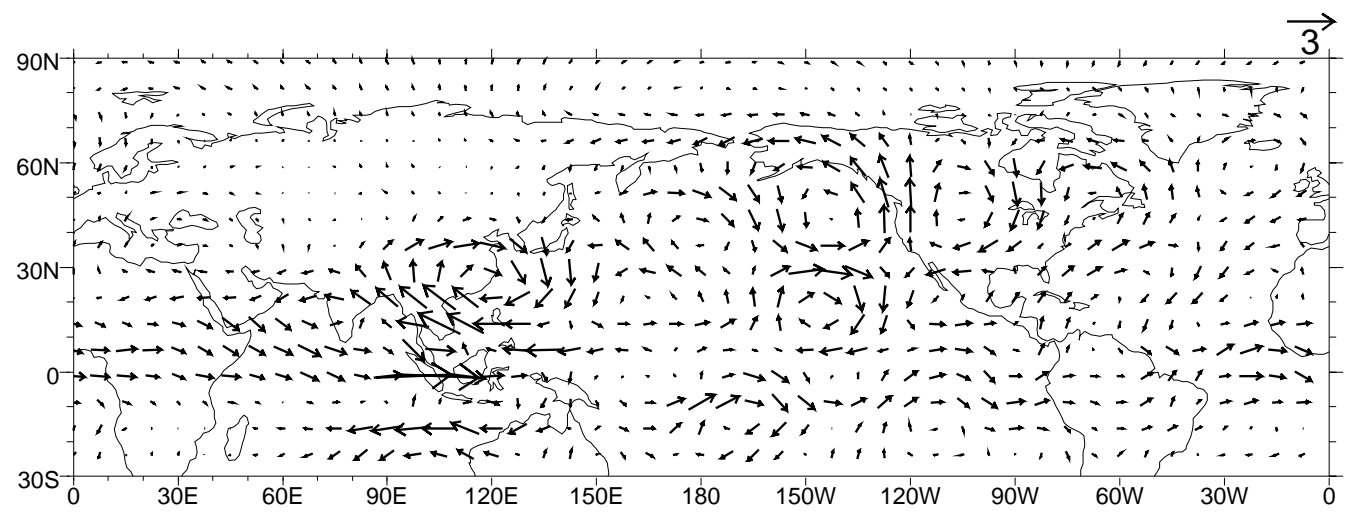

Figure 11. The sum of the 200-hPa vector wind model responses corresponding to opposite phases of the MJO cycle, at $t=6$ and $t=30$. The reference vector has magnitude $3 \mathrm{~m} \mathrm{~s}^{-1}$.

There are nonlinearities in the tropics as the exact shape of the equatorial wave response differs with the sign of the heating anomalies between $t=6$ and $t=30$. However, the most coherent difference is in the extratropical wave train over the North Pacific and North America. The difference pattern in Fig. 11 is similar to the model pattern at $t=30$, i.e., similar to that at $t=6$ but with opposite sign, hence the extratropical response at $t=30$ is stronger than that at $t=6$. Therefore, the mid-latitude response is weaker when there is anomalous tropical cooling to the east of anomalous heating. This is in contrast to the two-level model results of Bladé and Hartmann (1995) who found that the midlatitude response is inhibited when there is cooling to the west of heating, which they attributed to the effect of anomalous easterly flow on the equator. However, the stronger mid-latitude model response shown here at $t=30$ (Fig. 11) occurs during the phase of the MJO when the Pacific jet is stronger and extended. The jet would then act as a more efficient waveguide (Hoskins and Ambrizzi 1993; Matthews and Kiladis 1999b), trapping barotropic Rossby waves and leading to a larger wave amplitude downstream over North America.

\section{(d) Extratropical anomalies over the North Pacific and North America}

The origin of the extratropical anomalies over the Pacific sector were examined further by rerunning the integration that started at $t=39$ (Fig. 10a), but with the tropical heating switched off after day 9. The resulting vector wind anomalies at day 19 can be compared with those from the original integration at day 19 (Fig. 12). The forced equatorial wave response has disappeared. However, the extratropical circulation anomalies are very similar, both exhibiting the North Pacific extratropical structure with downstream dispersion. In particular there are the remnants of the Northern Hemisphere anticyclone-cyclone structure near the date line and the wave dispersion from this region over the North American and Atlantic regions and also through the westerly duct over the equatorial eastern Pacific into the Southern Hemisphere and over South America.

Given the robustness of these extratropical patterns we document the sign of the polarity in the extratropical structure in the North Pacific for Rossby waves forced by 


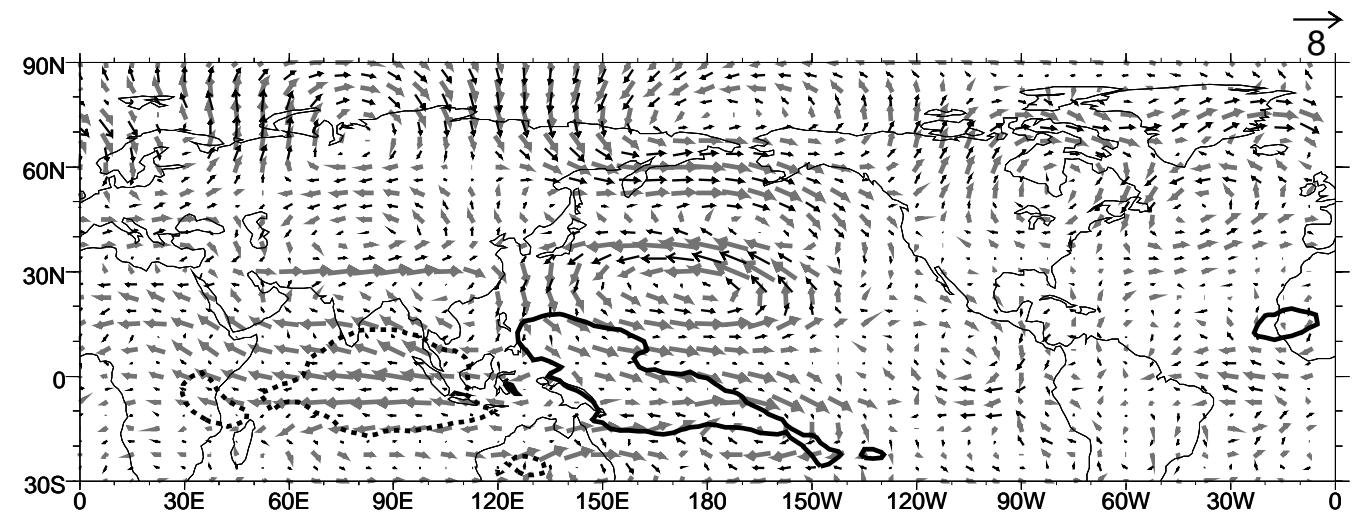

Figure 12. Model 200-hPa wind vector anomalies for day 19 (corresponding to $t=0$ of the MJO cycle) of the integration starting at $t=39$ (grey arrows). The corresponding field from a repeat of the integration with the heating switched off after day 9 is shown by the black arrows. The reference vector has magnitude $8 \mathrm{~m} \mathrm{~s}^{-1}$.

heating at different longitudes in the $\mathrm{MJO}$ active region from $60^{\circ} \mathrm{E}$ to $180^{\circ} \mathrm{E}$. Jin and Hoskins (1995) showed day 15 results for idealised fixed elliptical heating centred at $60^{\circ} \mathrm{E}$, $120^{\circ} \mathrm{E}$ and $180^{\circ} \mathrm{E}$. If the sign of the pattern is defined as positive if there were positive zonal wind anomalies near $45^{\circ} \mathrm{N}, 180^{\circ} \mathrm{E}$ with a cyclonic anomaly to the north and an anticyclonic anomaly to the south, these integrations led to negative, neutral and positive patterns, respectively. To give more resolution of the dependence on longitude, we show in Fig. 13 the day 15 results for similar idealised fixed monopolar heating centred at $90^{\circ} \mathrm{E}$ and $150^{\circ} \mathrm{E}$, respectively. The extratropical structure is again obtained, this time with negative and positive signs, respectively. Therefore, in the MJO active region a constant positive heating anomaly near the equator leads to the triggering of a negative North Pacific pattern when centred west of about $120^{\circ} \mathrm{E}$ and a positive pattern when centred to the east. Assuming linearity, for a negative heating anomaly the signs are reversed.

(a) Heating at $90 \mathrm{E}$

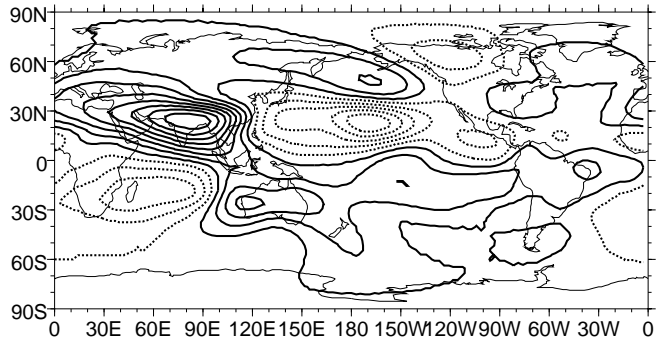

(b) Heating at $150 \mathrm{E}$

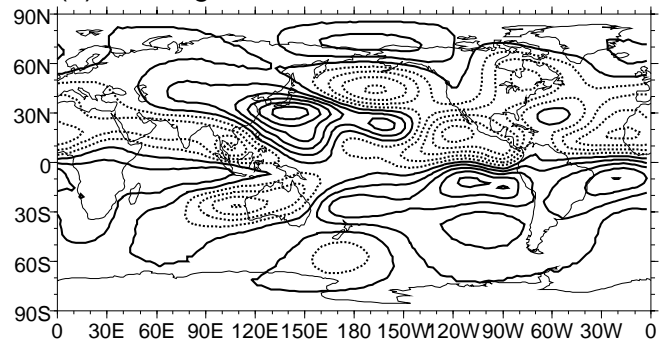

Figure 13. Model 200-hPa streamfunction anomalies for day 15 for integrations with idealised fixed elliptical heating centred on the equator at (a) $90^{\circ} \mathrm{E}$, (b) $150^{\circ} \mathrm{E}$. Contour interval is $1.25 \times 10^{6} \mathrm{~m}^{2} \mathrm{~s}^{-2}$; negative contours are dotted.

Considering the MJO heating as suggested by the OLR in Fig. 1 and given for two phases in Fig. 3, we can now estimate the sign of the North Pacific pattern likely to be triggered by the MJO forced Rossby waves during each phase of its cycle. From about $t=36$ to $t=48$ (equivalent to $t=0$ ) both the heating and the cooling would lead to the mode with a negative sign. Similarly, from about $t=12$ to $t=24$ both would lead to a positive mode. The MJO simulation results shown in Fig. 10 and for other phases actually exhibited a negative mode from about $t=42$ to $t=12$ and a positive mode from 
about $t=18$ to $t=36$. For the observed MJO (Fig. 1 ) the corresponding days were the same. These timings are consistent with the tropical forcing arguments given above and of order 6-12 day propagation and set-up time.

\section{(e) Model sensitivity}

Barotropic normal modes are not robust to changes in model setup (Borges and Sardeshmukh 1995). If the model extratropical response to the MJO heating is due in large part to such barotropic modal growth, then the model response may be expected to be sensitive to changes in model parameters. Also, steady state solutions to tropical heating in a baroclinic model display a high sensitivity to the longitudinal positions of the heating and to the basic state (Ting and Sardeshmukh 1993). However, the direct response to fixed tropical heating is not sensitive to these factors (Jin and Hoskins 1995). In this section, the sensitivity of the direct model response to the time dependent MJO heating anomalies is assessed. The day 15 response of the integration starting at $t=9$ is used to illustrate this sensitivity; the standard integration is shown in Fig. 14a.

First, the model sensitivity to damping is examined. The day 15 200-hPa streamfunction anomalies from reruns of the standard integration but with zero damping (Fig. 14b) and double damping (Fig. 14c) have very similar spatial patterns, particularly in the extratropics, but with slightly larger and smaller amplitudes, respectively. Hence, the pattern of the extratropical response to the MJO tropical heating anomalies does not appear to be sensitive to realistic changes to the damping, supporting the hypothesis of a forced response rather than the triggering of an unstable growing extratropical mode (Borges and Sardeshmukh 1995).

The sensitivity of the response to the basic state is now considered. The integration was repeated again, but using a basic state with a stronger, extended Pacific jet, representative of El Niño conditions, following Matthews and Kiladis (1999b). During El Niño events, observed MJO convective anomalies tend to propagate further eastward than usual, into the central Pacific (Kessler 2001). However, the same MJO heating patterns were used in the model to isolate the effect of just changing the basic state on which the response developed. The response at day 15 on this El Niño DJF basic state (Fig. 14d) is very similar to that on the climatological DJF basic state (Fig. 14a) over most of the globe. Individual streamfunction anomalies in the former can be unambiguously matched with corresponding streamfunction anomalies in the latter. Not surprisingly, the largest differences are over the central and eastern Pacific where the largest differences in the basic state are. In particular, the anticyclonic flow over western North America is weakened and the cyclonic anomaly over eastern North America is shifted northward in the integration with the El Niño basic state.

The day 15 response from an integration on a basic state with a weak and retracted Pacific jet, representative of La Niña conditions (Matthews and Kiladis 1999b), is shown in Fig. 14e. Again, the model response is very similar to that with the climatological average basic state (Fig. 14a) over most of the globe. In this case, the anticyclonic anomaly over western North America and the cyclonic anomaly over eastern North America has strengthened in the integration on the La Niña basic state. These results are consistent with the nonlinear response in the model MJO cycle (Fig. 11), which was attributed to the strength of the Pacific jet waveguide in section 5d. The strongest extratropical model response over North America is seen when the Pacific jet was strong and extended eastward, at $t=30$ in the standard MJO model cycle (Fig. 11) or with a La Niña basic state (Fig. 14e), while a weaker extratropical response was seen when the Pacific jet was weak, at $t=6$ in the MJO cycle (Fig. 10b) or with an El Niño basic state (Fig. 14d). The 
(a) Standard

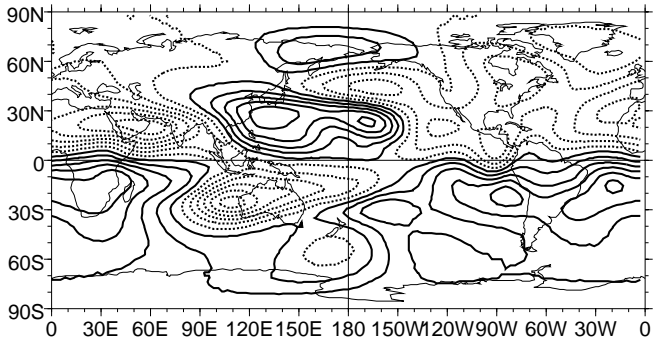

(b) No damping

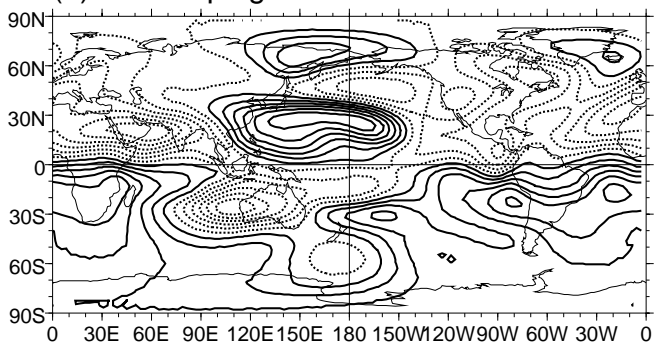

(c) Double damping

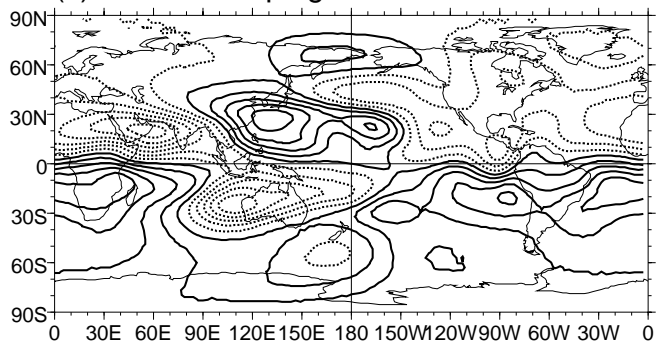

(d) El Nino basic state

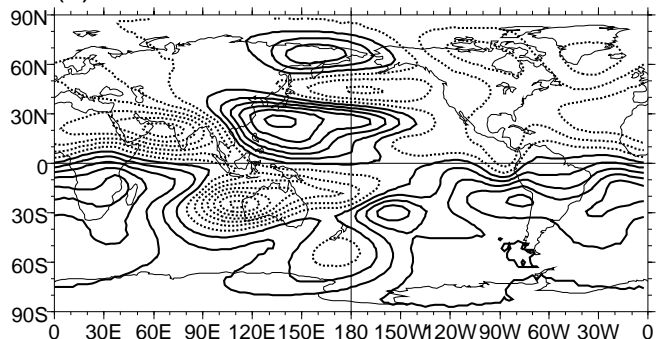

(e) La Nina basic state

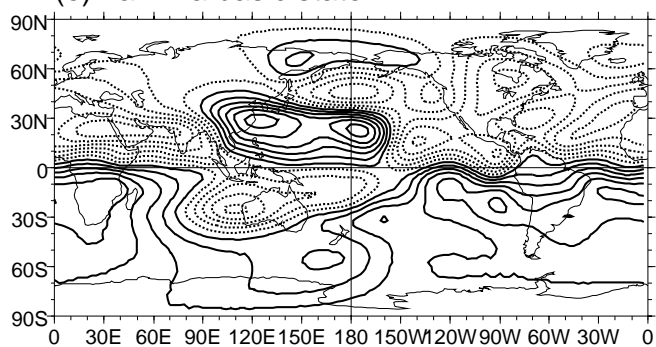
(f) Shallow heating

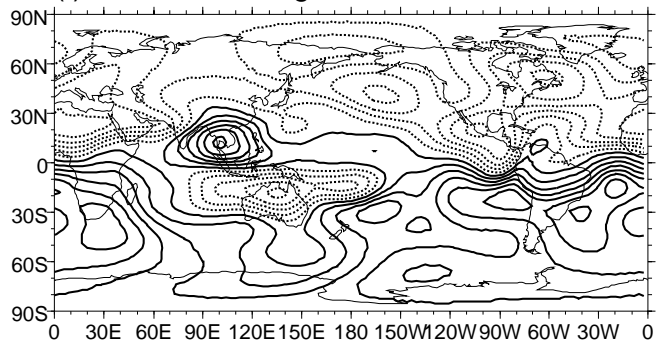

Figure 14. Model 200-hPa streamfunction anomalies for day 15 of the sensitivity experiments. (a) Standard integration, (b) no damping, (c) double damping, (d) El Niño basic state, (e) La Niña basic state, (f) shallow heating. Contour interval is $1.25 \times 10^{6} \mathrm{~m}^{2} \mathrm{~s}^{-2}$; negative contours are dotted.

effect of the El Niño and La Niña basic states appears to be qualitatively of the same importance as the effect of nonlinearity within the standard MJO cycle.

The model MJO life cycle in Fig. 10 was calculated assuming a 48-day periodicity to the MJO tropical heating anomalies. However, the MJO is not a strictly periodic phenomenon at a single frequency, but covers a broad range of frequencies with periods between approximately 30 and 70 days (e.g., Hendon and Salby 1994). Hence the sensitivity of the model response to the rather arbitrary 48-day periodicity of the forcing needs to be considered. The model integrations presented in Figs. 12 and 13 imply that the response is not highly sensitive to the periodicity of the forcing. In Fig. 12, the tropical heating was switched off after day 9 of the integration, but the extratropical anomalies develop in a very similar manner to the integration with the full heating. The extratropical response in the idealised fixed heating experiments of Jin and Hoskins (1995) and those shown in Fig. 13, which were discussed in section 5d and the series of staggered fixed heating experiments discussed in section 4 , are also similar to those with the time-dependent MJO heating in Fig. 10, again implying that the important time scale is the one to two weeks for an extratropical anomaly to develop in response to tropical heating, rather than the time scale or propagation speed of the tropical heating anomalies themselves. 
Finally, an integration was carried out in which the maximum in the heating profile was lowered from $400 \mathrm{hPa}$ to $650 \mathrm{hPa}$ (Fig. 14f). The response pattern is similar but its amplitude is weaker with the "shallow" heating, in agreement with Ting and Sardeshmukh (1993). However, calculation of the full three-dimensional heating from the NCEP/NCAR reanalysis showed that the maximum heating level is generally near 400 $\mathrm{hPa}$, and the idealised vertical profile used in the standard integrations is realistic.

Hence, the direct extratropical model response to MJO heating anomalies is robust to large changes in the model setup, specifically the damping time scales, basic state, periodicity of the forcing and height of the heating maximum.

\section{Conclusions}

A cycle of global MJO circulation anomalies was constructed from 21 northern winter seasons of OLR and NCEP/NCAR reanalysis data. The results were generally consistent with previous studies using shorter data sets with the addition of some new results. In particular, there were statistically significant circulation anomalies covering much of the globe, including evidence of wave trains in the Northern and Southern Hemispheres and cross-equatorial wave propagation over the eastern Pacific.

To examine the cause of the MJO circulation anomalies, a primitive equation model was initialised about the three-dimensional DJF climatological-mean flow and forced with a time-dependent heating derived from the observed MJO heating anomalies over the warm pool. The response to the MJO heating was analysed for the first three weeks of the model integration before baroclinic instability effects began to dominate. A staggered series of such integrations allowed a complete model MJO cycle to be constructed, which could be directly compared with the observed MJO cycle. The tropical response in the model was shifted westward relative to the observations by approximately $20^{\circ}$ longitude, which corresponds to a time lag of about 5 days. This was possibly due to the lack of damping (cumulus friction) in the heating region. Once this shift was taken into account, the model simulated the observed global MJO anomalies well. It reproduced nearly all the major circulation features, although the amplitudes and exact positions of the features differed slightly. The tropical and extratropical MJO model anomalies were approximately linear, in that the two halves of the model MJO cycle were very similar, apart from a sign change, even though the response to the heating anomalies included the non-linear dynamical terms.

Over the North Pacific, a coherent extratropical structure appeared to be forced. In its positive phase this consisted of a strengthened and extended Pacific jet with an anticyclonic anomaly to the south and a cyclonic anomaly to the north, together with a downstream anticyclonic anomaly over western North America and a cyclonic anomaly over eastern North America. In the observed MJO, this pattern was present between $t=18$ and $t=36$ in its positive phase and between $t=42$ and $t=12$ in the next 48 -day MJO cycle in its negative phase. The extratropical pattern remained almost stationary, even though the tropical heating anomalies moved significantly eastward during these phases. The model results simulated this behaviour well and were consistent with the extratropical response to tropical heating with a one-to-two week set up time.

The model response to the time dependent MJO heating was relatively insensitive to realistic changes in the imposed damping and the basic state on which the anomalies developed, consistent with the direct response to fixed tropical heating of Jin and Hoskins (1995), but in contrast to the studies of the steady state response to tropical heating (Ting and Sardeshmukh 1993) and of the growth of internal barotropic normal modes (Borges and Sardeshmukh 1995). Hence the results presented here support the paradigm of a 
forced extratropical response to tropical MJO heating, which then interacts with the mean flow, rather than the triggering and subsequent growth of unstable, extratropical normal modes.

The overall conclusion from this investigation is that the MJO has an associated global evolving circulation in the upper troposphere that is predominantly a direct response to its tropical heating anomalies. The tropical convective outflow anomalies lead to Rossby wave sources, sometimes in preferred locations with respect to the ambient flow. The Rossby waves propagate eastwards on great circle like ray paths, and are guided by the ambient jets. In preferred locations they are able to extract energy from the ambient flow in manner similar to that of unstable barotropic normal modes.

There are many factors that could lead to the differences between the observed global MJO evolution and that shown in our simple model. One such factor is the lack of transient wave activity in the model. The MJO significantly modulates the higher frequency transient waves during its life cycle, particularly over the central and eastern Pacific (Matthews and Kiladis 1999a). During the phase of the MJO with a retracted Asian-Pacific jet (corresponding to $t=0$ in this study) there is an enhanced equatorward propagation of higher frequency waves through the westerly duct. These higher frequency waves have associated convective heating and poleward momentum transports that would feed back onto the slowly varying MJO. These processes were not represented in the model used here, even though they are important on these time scales (Winkler et al. 2001). The lack of transient wave feedback may be the reason that significant MJOrelated fluctuations found in the observational data in the North Atlantic region are not simulated in the model.

The model presented here considered the propagation and development of anomalies forced by tropical convection on a climatological average basic state. MJO events in the real atmosphere would interact with other pre-existing circulation anomalies (Winkler et al. 2001) that could systematically affect the development of "MJO" extratropical anomalies. Pre-existing high-frequency baroclinic waves could also amplify preferentially during a particular phase of the MJO and feed back onto the developing MJO extratropical anomalies.

The model MJO cycle shown here has implications for global medium-range weather forecasting on lead times of two to four weeeks, as a significant fraction of the observed intraseasonal circulation could be attributed to the MJO (up to $70 \%$ for the tropical winds and $36 \%$ in the northern extratropics). In the tropics, the dynamical response to the MJO convection anomalies was established in a few days, so for medium-range prediction the time evolution of the tropical MJO convection needs to be accurately forecast. Currently, dynamically based numerical weather prediction models do not accurately predict the evolution of the tropical MJO convective anomalies and this leads to errors in the extratropical forecast due to erroneous tropical divergent outflow and associated Rossby wave source (Hendon et al. 2000). Statistically based forecasts have shown some success (e.g., Waliser et al. 1999). The time lag of some one to two weeks for the extratropical circulation to respond to the tropical convection anomalies implies that development of the tropical convective anomalies after one week is of less importance for predicting the extratropical anomalies in the second week.

\section{ACKNOWLEDGEMENT}

The authors thank an anonymous reviewer and Grant Bigg for comments that helped to greatly improve the manuscript. The OLR and NCEP-NCAR reanalysis data were provided through the NOAA Climate Diagnostics Center (http://www.cdc.noaa.gov). 
Bladé, I. and Hartmann, D. L.

Borges, M. D. and

Sardeshmukh, P. D.

Ferranti, L., Palmer, T. N., Molteni, F. and Klinker, E.

Hendon, H. H., Liebmann, B., Newman, M., Glick, J. D. and Schemm, J. E.

Hendon, H. H. and Salby, M. L.

Hendon, H. H. and Salby, M. L. 1996

Higgins, R. W. and Mo, K. C. 1997

Hsu, H.- H.

Jin, F.- F. and Hoskins, B. J.

Kalnay, E., and coauthors.

Kessler, W. S.

Kiladis, G. N. and

Weickmann, K. M.

Knutson, T. R. and

Weickmann, K. M.

Liebmann, B. and Smith, C. A.

Madden, R. A. and Julian, P. R. 1972

Mapes, B. E. and Wu, X. Q.

Matthews, A. J.

Matthews, A. J. and

Kiladis, G. N.

Matthews, A. J. and

Kiladis, G. N.

Mo, K. C. and Higgins, R. W.

Sardeshmukh, P. D. and

Hoskins, B. J.

Simmons, A. J., Wallace, J. M. and Branstator, G. W.

Ting, M. and

Sardeshmukh, P. D.

Waliser, D. E., Jones, C.,

Schemm, J. -K. E. and

Graham, N. E.

Winkler, C. R., Newman, M. and Sardeshmukh, P. D.

\section{REFERENCES}

1995 The linear and nonlinear extratropical response of the atmosphere to tropical intraseasonal heating. J. Atmos. Sci., 52, 4448-4471

1995 Barotropic Rossby-wave dynamics of zonally varying upper-level flows during northern winter. J. Atmos. Sci., $\mathbf{5 2}, 3779-3796$

1990 Tropical-extratropical interaction associated with the 30 60 day oscillation and its impact on medium and extended range prediction. J. Atmos. Sci., 47, 2177-2199

2000 Medium-range forecast errors associated with active episodes of the Madden-Julian oscillation. Mon. Wea. Rev., $\mathbf{1 2 8}, 69-86$

1994 The life cycle of the Madden-Julian oscillation. J. Atmos. Sci., 51, 2225-2237

Planetary-scale circulations forced by intraseasonal variations of observed convection. J. Atmos. Sci., 53, 1751-1758

997 Persistent North Pacific circulation anomalies and the tropical intraseasonal oscillation. J. Climate, 10, 223-244

1996 Global view of the intraseasonal oscillation during northern winter. J. Clim., 9, 2386-2406

1995 The direct response to tropical heating in a baroclinic atmosphere. J. Atmos. Sci., 52, 307-319

1996 The NCEP/NCAR 40-year reanalysis project. Bull. Am. Meteorol. Soc., 77, 437-471

2001 EOF representations of the Madden-Julian oscillation and its connection with ENSO. J. Climate, 14, 3055-3061

1992 Circulation anomalies associated with tropical convection during northern winter. Mon. Weather Rev., 120, 19001923

1987 30-60 day atmospheric oscillations: composite life cycles of convection and circulation anomalies. Mon. Weather Rev. 115, 1407-1436

1996 Description of a complete (interpolated) OLR dataset Bull. Amer. Meteor. Soc., 77, 1275-1277

Description of global scale circulation cells in the tropics with a 40-50 day period. J. Atmos. Sci., 29, 1109-1123

2001 Convective eddy momentum tendencies in long cloudresolving model simulations. J. Atmos. Sci., 58, 517-526

2000 Propagation mechanisms for the Madden-Julian oscillation. Q. J. R. Meteorol. Soc., 126, 2637-2652

$1999 \mathrm{a}$ The tropical-extratropical interaction between highfrequency transients and the Madden-Julian oscillation. Mon. Wea. Rev., 127, 661-677

1999b Interactions between ENSO, transient circulation and tropical convection over the Pacific. J. Climate, 12, 3062-3086

1998 Tropical convection and precipitation regimes in the western United States. J. Climate, 11, 2404-2423

1988 The generation of global rotational flow by steady idealized tropical divergence. J. Atmos. Sci., 45, 1228-1251

1983 Barotropic wave propagation and instability, and atmospheric teleconnections patterns. J. Atmos. Sci., 40, 13631392

1993 Factors determining the extratropical response to equatorial diabatic heating anomalies. J. Atmos. Sci., 50, 907918

1999 A statistical extended-range tropical forecast model based on the slow evolution of the Madden-Julian Oscillation. $J$. Climate, 12, 1918-1939

2001 A linear model of wintertime low-frequency variability. Part I: Formulation and forecast skill. J. Climate, 14, 4474-4494 